\title{
A POTENTIAL LINK BETWEEN INFANT-DIRECTED SPEECH AND EVOLUTION OF VOCAL COMMUNICATION
}

\author{
REIKO MAZUKA ${ }^{1 *}$, TADAHISA KONDO ${ }^{2}$, and AKIKO HAYASHI ${ }^{3}$ \\ *Corresponding Author: mazuka@brain.riken.jp \\ ${ }^{1}$ Laboratory for language development, RIKEN BSI, Saitama, Japan \\ ${ }^{2}$ Kogakuin University, Tokyo, Country \\ ${ }^{3}$ Tokyo Gakugei University, Tokyo, Japan
}

Adults modify their speech when they talk to infants and young children. This style of speech is called "Infant-directed speech" (IDS). Research has shown that IDS differs from ADS in multiple ways, for example, phonologically, lexically, syntactically, as well as pragmatically. Many of these features have been argued to contribute to attracting and maintaining infants' attention, communicating affects, as well as facilitating their language acquisition (Soderstrom, 2007, for review). Yet, it is still not clear how adults would know what to say in IDS. In this presentation, we focus on the specific ways IDS favors certain segments over others and ask how adults would know which segments to use selectively in IDS.

The prominent view in the field is that mothers (and other adults) fine-tune their production to infants' capabilities such that segments that are produced early by infants are favored over those that are not produced until later (the "fine-tuning hypothesis," Cross, 1977). The implication of this hypothesis is that mothers' productions are either imitations of children's immature production, or more generally learned through their interaction with their children. In the present paper, we argue for an alternative possibility that is based on Morton's Motivation-Structure Rule Hypothesis, MSRH (1977). He proposed that there is a general relationship between the physical structures of sounds and the motivation underlying their use in animal communication. Considering that human adults' use of IDS is also motivated by their desire to communicate their intensions and affects with infants, the selective use of certain sounds in IDS may be also explained by MSRH. If true, it predicts that IDS would arise from MSRH, and need not be learned from infants. 
We tested these predictions in a series of rating studies with Japanese mothers with young infants and college aged Japanese adults with minimal contact with infants and young children. One way in which selective segments are used more frequently in IDS is the use of specialized vocabulary items in IDS, Infant-Directed Vocabulary (IDV). Mothers and college aged adults were asked to rate large sets of nonsense words in terms of how well each item sounds like an IDV on a 7-point Likert scale "sounds like a very good IDV word" (7) to "does not sound like an IDV word at all" (1) (Mazuka, Hayashi, Kondo, 2017a). A different group of college aged adults were asked to rate the same set of words in terms of how good they sound as a Japanese word. Stimuli were created such that we can test whether the following factors would result in higher IDV ratings; 1) presence of specific vowels, 2) consonants, and 3) the prosodic form of the word (Mazuka, Hayashi, Kondo, 2017b).

The results revealed that college aged adults were highly accurate in rating nonsense words as "sounds like a good IDV" when they contained vowels and consonants that are produced early by Japanese children (e.g., /p, b, m/ and /a/), while rating those with late-produced segments (e.g., fricatives (/s, z/) as "does not sound like a good IDV." College aged adults' ratings were highly consistent with the ratings of the mothers as shown in Table 1 . The results also revealed that a word that sounds like a good IDV is clearly distinct from those that sound as a good Japanese words.

These results showed that the experience of interacting with children is not necessary for a native speaker of Japanese to have a sense of what a good IDV should sound like in Japanese, which is consistent with the prediction of MSRH. Further explorations into the link between IDS and vocal communication of animals could elucidate the how language communication may have evolved.

Table 1. Correlations among Mothers' ratings of IDV-ness, college age adults' IDV-ness, and college age adults' Japanese-ness ratings.

\begin{tabular}{cccc}
\hline & Mothers' IDV-ness & $\begin{array}{c}\text { College-age adults' IDV- } \\
\text { ness }\end{array}$ & $\begin{array}{c}\text { College-age adults' } \\
\text { Japanesenes }\end{array}$ \\
\hline Mothers' & 1.00 & 0.867 & -0.02 \\
IDV-ness & & $\mathrm{P}<.001$ & n.s. \\
College-age adults' & 1.00 & -0.23 \\
IDV-ness & & $\mathrm{p}<.001$ \\
College-age adults' \\
Japanese-ness
\end{tabular}




\section{References}

Cross, T. G. (1977). "Mothers' speech adjustments: The contributions of selected child listener variables." In K. Snow \& C. A. Ferguson (eds.), Talking to children: Language input and acquisition (pp. 151-188). Cambridge: Cambridge University Press.Pinker, S., \& Bloom, P. (1990). Natural language and natural selection. Behavioral and Brain Sciences, 13, 707-784.

Mazuka, R., Kondo, T., \& Hayashi, A. (2017a). "Sounds of infant-directed vocabulary: Learned from infants' speech or part of linguistic knowledge?" Journal of the Phonetic Society of Japan, 21(1), 45-58.

Mazuka, R., Kondo, T., \& Hayashi, A. (2017b). "Good infant-directed words" do not sound like "good Japanese words." In S. Tanaka et al. (Eds.), On'in kenkyu-no shin-tenkai [New directions in phonological research]. 202-219. Kaitaku-sha, Tokyo.

Morton, E. S. (1977). "On the occurrence and significance of MotivationStructural Rules in some bird and mammal songs." American Naturalist, $111,855-869$.

Soderstrom, M. (2007). Beyond babytalk: Re-evaluating the nature and content of speech input to preverbal infants. Developmental Review, 27, 501-532. 